\title{
Evaluation of the correlation between enabling the personnel and the occupational satisfaction and the organizational commitment from a strategic point of view in Samsung Corporation Representation in Iran
}

\author{
${ }^{1}$ Pouya fattahi, ${ }^{2}$ Zeinolabedin amini sabegh \\ ${ }^{1,}$ Departmen ${ }^{t}$ of executive management, college of management, Saveh Science and Research branch, Islamic \\ Azad University, Saveh, Iran. \\ ${ }^{2}$. Departmen ${ }^{t}$ of Public management, Islamic Azad University, saveh branch, Saveh, Iran
}

\begin{abstract}
The personnel are the base of the success of the company in achieving to the competitive advantages and creation of the value added; so they should be behaved as an important and critical strategic resource. Therefore, the business strategy in today organizations is focused on the human resources. Enabling the personnel or involving the personnel in the organizational decisions, is a necessary management tool in order to control and conduct the human resources for increasing the efficiency. Also this should be noticed that although considering the enabling of the personnel can result in increasing the self-confidence of the personnel and improving their performance, but considering other issues such as occupational satisfaction and organizational commitment can have an important role in improvement of the performance and increasing the motive of the personnel. The purpose of the present study is to evaluate the relation between enabling, organizational commitment and the occupational satisfaction from a strategic point of view for the personnel who work in Samsung Corporation during 1391-1392. The present study in term of the objective is an operational and functional research and in term of the methodology it is a field finding research. The method used in the present study is the correlation method. The field (questionnaire) and library methods are used in order to collect data. For 35 professional and special questions in the questionnaire the five-item scale is used and for the questions related to sex, age and education level, the nominal scale is used. In the present study four variables namely the enabling, occupational satisfaction, occupational view and organizational commitment are considered, and the correlations between these four variables were investigated separately. The statistical population for the present study is a limited one, and includes all of the personnel is Samsung Corporation which is 220 employees. The framework for sampling in the present study is the list of the whole personnel working in Samsung Corporation and the employees complete the questionnaires personally. In order to define the population volume and size with regard to the sampling framework, the suitable formulae was used, and 136 employees was defined as the size of the population, after distributing the questionnaires, 134 of them were returned and collected. The sampling method used in this research is a non-random judicativesampling. In the present study, the Spearman Correlation Coefficient is used in order to investigate the hypotheses and the significance and meaningfulness of the correlations between the variables in each of the hypotheses is investigated with this coefficient. The correlation coefficient for the enabling and occupational satisfaction variables was -0.391, and for the enabling and the organizational commitment variables was 0.253 , and for the enabling and the occupational view variables was 0.495, and for the occupational view and the organizational commitment variables was 0.401, and for the occupational view and the occupational satisfaction variables was 0.594, and for the organizational commitment and the occupational satisfaction was 0.412 .
\end{abstract}

Keywords: Enabling, Occupational Satisfaction, Occupational View, Organizational Commitment, Strategic Point of view

\section{Introduction}

Today the organizations are affected by some factors such as increasing the world competition, instant changes, need to have quality and after sale services and limited resources and so on, and the organizations because of these factors are under heavy pressures. After years of experiences, the world has reached to this conclusion that if an organization wants to be pioneer is its related field and does not lose the competition, it should have a professional and expert human resources which should be innovative and with high motivations.The human resources are the real wealth of an organization. There are direct correlations between the human resources and the efficiency in the organizations. From the most important considerations in the successful businesses in the world, we can mention to collecting the knowledgeable human resources and wisdom which can lead to a revolution in the organizations which these resources belong to. A successful organization is composed of the people with the organizational culture, and with the common thoughts and 
objectives who work in groups in a flexible organization and share their experiences and knowledge with their managers while being interested in improvement of the organization. Therefore each personnel will feel ownership about the organization and the responsibility which are assigned to him.

Using from the potential capabilities of the human resources for each organization is a great advantage. In personal efficiency, the organization uses from the potential personal capabilities and talents in order to improve the organization and through using from the potential powers and great capabilities improves the employee personally and makes him in the same direction as the organization. Therefore for achieving to the goals of the organization, the effective management of these resources is very important. For this purpose, improvement, growth, and gradation of the personnel capabilities in the recent years have been considered by many professional and experts in the field of the human resources as the label of enabling the personnel. As the organizations face with the organizational challenges, and consider the sustainable improvement as their priority, then more supports and commitments from the personnel and their more involvement in the operations are needed for this purpose.

\section{Problem Description}

Generally, in the contemporary era the organizations do not use from the most important resource which is the thinking power of the employees - in order to develop and improve in a proper way. It is expected that the organization personnel be competent technically, but this competency mostly is limited to the responsibilities and the organizational discipline. Rarely the employees are asked to help in improving the weak administrative operations, or define the best type of the organizations in order to do the responsibilities for the employees. In problem description of the research it should be mentioned that undoubtedly paying attention to the proper human resources and considering the needs of the organization with regard to the efficient human resources, can lead to achieving to the competitive advantages in comparison to the other competitors and absorbing the customers, then the organization should pay attention to some issues such as enabling the employees, occupational satisfaction and organizational commitment of their personnel. The issues which ignoring them usually leads to many various problems for the organizations. The employees, who think they are the owner of the organization and its operations, feel the need of being related and connected to the organization more than the others. In the present study we try to investigate the correlation between the enabling the personnel, occupational satisfaction and the organizational commitment; because many of the organization's problems will be solved by its human resources by clearing and abstract consideration of the organization to these problems.

\section{Hypotheses}

1. There is a significant correlation between enabling the employees and their occupational satisfaction from a strategic point of view.

2. There is a significant correlation between enabling the employees and their organizational commitment from a strategic point of view.

3. There is a significant correlation between enabling the employees and their occupational view from a strategic point of view.

4. There is a significant correlation between occupational satisfaction and their occupational satisfaction from a strategic point of view.

5. There is a significant correlation between occupational view of the employees of an organization and their organizational commitment from a strategic point of view.

\section{Questions of the Research}

This section includes 35 questions related to the research variables ( 8 questions about enabling the personnel, 10 questions about occupational satisfaction, 9 questions about the organizational commitment, and 8 questions about the occupational point of view). In designing this section we have tries to make the questions and the questionnaire understandable. The professional section questions are presented in Tables 2-3 question by question. Also more comprehensive information about the variables and their indexes are provided in Table 3-3. Table of the variables and number of the professional questions of the questionnaire

\begin{tabular}{|c|c|}
\hline Variable & Questions Number \\
\hline Enabling the Personnel & $1-8$ \\
\hline Occupational Satisfaction & $9-16$ \\
\hline Organizational Commitment & $17-25$ \\
\hline Occupational point of view & $26-35$ \\
\hline Total & 35 \\
\hline
\end{tabular}


For the present study, the Cronbach alpha value was calculated by the SPSS software. For this purpose, a prototype of the questionnaire containing 30 questionnaire was prepared and examined, and the ideas from the questioners were considered; then by the information obtained from theses questionnaires and by using from the statistical data obtained from SPSS software, the durability coefficient was calculated for each of the variables and for the whole set by the Cronbach Alpha method; then the questionnaires were modified by changing the items and texts of the questions and again 30 other questionnaires were distributed to be completed, and the results of their Cronbach Alpha value are provided in the following table:

Table of the Cronbach Alpha Values

\begin{tabular}{|l|c|c|}
\hline Variables & Number of the Questions & Cronbach Alpha \\
\hline Enabling the personnel & 8 & 0.863 \\
\hline Occupational View & 10 & 0.792 \\
\hline Organizational Commitment & 9 & 0.802 \\
\hline Occupational Satisfaction & 8 & 0.823 \\
\hline
\end{tabular}

\section{Data Analysis}

\section{Population Average Test}

In this section by using from a population average test we try to investigate this fact that how is the situation and condition of the studied variables in this research. The design of its hypotheses is as follow:

Null Assumption: Associated Variable Average is smaller or equal to 3

$\left(H_{0}: \mu \leq 3\right)$

Opposite Assumption: Associated Variable Average is greater than $3\left(H_{1}: \mu>3\right.$ )

In the following Table, the significance value, degree of freedom of the test (the size of the population minus 1), the significance level (sig), and upper and lower limits for the averages are provided. If sig is smaller than 0.05 and the lower and upper limits both are positive, then the hypotheses is accepted.

\section{Population Average test}

\begin{tabular}{|c|c|c|c|c|c|}
\hline \multicolumn{5}{|c|}{ Confidence Level 0f 95\% } \\
\hline Upper Limit & Lower Limit & Significance Level & $\begin{array}{c}\text { Degree of } \\
\text { Freedom }\end{array}$ & t-Student & Variable \\
\hline-0.861 & -1.098 & 0.000 & 133 & -16.300 & Enabling the Personnel \\
\hline-0.600 & -0.799 & 0.000 & 133 & -13.908 & Occupational Point of View \\
\hline-0.385 & -0.564 & 0.000 & 133 & -10.513 & Organizational Commitment \\
\hline-0.172 & -0.371 & 0.000 & 133 & -5.382 & Occupational Commitment \\
\hline
\end{tabular}

As it can be seen from the above Table, the significance level for all of the variables is lower than 0.05 and their upper and lower limits both are negative. Therefore it can be said that the average answers for all of the variables is smaller than 3 . It means that the enabling of the personnel is at a low level. The occupational satisfaction and the organizational commitment are low and the occupational point of view between all of the respondents in this population is at a low level.

\section{The correlation between the main independent and dependent variables:}

Before investigating this model through the structural equations, the correlation between the variables of this model was examined by the Pearson Test. In the following table the correlations for the variables are provided. The hypothesis test is provided as follow:

Null Assumption: There is no significant correlation between variables I and $\mathrm{j}$.

Current Assumption: There is a significant correlation between variables I and $\mathrm{j}$.

As it can be seen in the following table (In the following Table $r$ stands for correlation coefficient and sig stands for the significance level), because Sig value is smaller than 0.05 (level of error), hen the null assumption is rejected and therefore the correlation between the variables is significant.

The Table of the Correlations between the Variables

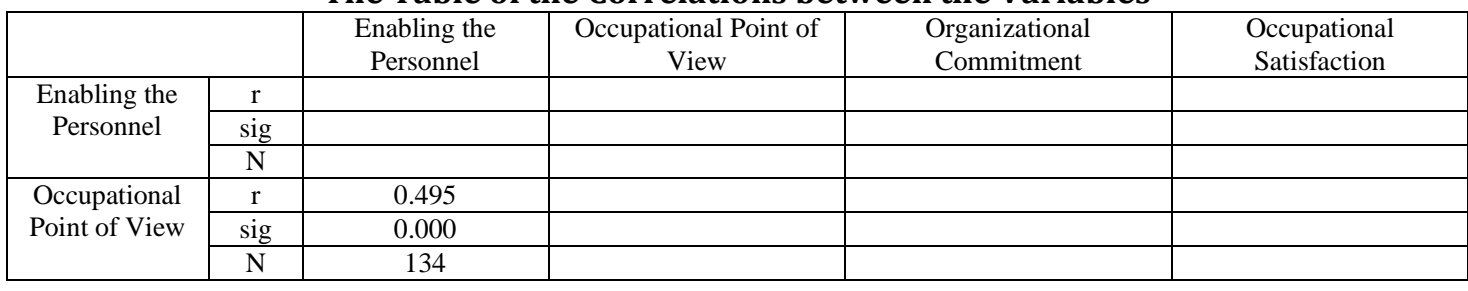




\begin{tabular}{|c|c|c|c|c|c|}
\hline Organizational & $\mathrm{r}$ & 0.253 & 0.401 & & \\
\cline { 2 - 6 } & $\mathrm{sig}$ & 0.003 & 0.000 & & \\
& $\mathrm{~N}$ & 134 & 134 & & \\
\hline Occupational & $\mathrm{R}$ & -0.391 & 0.594 & 0.412 & \\
\cline { 2 - 7 } Satisfaction & $\mathrm{sig}$ & 0.010 & 0.000 & 134 & \\
\cline { 2 - 7 } & $\mathrm{N}$ & 134 & 134 & 134 & \\
\hline
\end{tabular}

The interpretation for some of the observed correlations in the above table:

- There is correlation at the size of 0.495 between enabling the personnel and the occupational point of view; it means that with one unit of increase in enabling the personnel the observed increase in the occupational point of view will be equal to 0.495 and vice versa.

- There is correlation at the size of 0.253 between enabling the personnel and the organizational commitment; it means that with one unit of increase in enabling the personnel the observed increase in the organizational commitment will be equal to 0.253 and vice versa.

- There is correlation at the size of 0.401 between the occupational point of view and the organizational commitment; it means that with one unit of increase in occupational point of view the observed increase in the organizational commitment will be equal to 0.495 and vice versa.

\section{Analysis of the observed trend in the conceptual mode}

Trend Analysis (structural model) is a technique which represents the relations between the research variables (dependent and independent variables) simultaneously. Here, the conceptual model was examined by the structural equations and Lisrel Software. The results of the assumption of this examination are provided in summary in the following table.

\begin{tabular}{|c|c|c|c|}
\hline Hypotheses and Assumptions & Significance Value & Effect Level & $\begin{array}{c}\text { Description and } \\
\text { Interpretation }\end{array}$ \\
\hline $\begin{array}{c}\text { Enabling the personnel of an organization has a positive and } \\
\text { significant effect of their occupational satisfaction }\end{array}$ & -1.52 & -0.53 & $\begin{array}{c}\text { Smaller than } 1.96 \text { and } \\
\text { rejected }\end{array}$ \\
\hline $\begin{array}{c}\text { Enabling the personnel of an organization has a positive and } \\
\text { significant effect of their organizational commitment }\end{array}$ & 2.13 & 0.77 & $\begin{array}{c}\text { Greater than } 1.96 \text { and } \\
\text { accepted }\end{array}$ \\
\hline $\begin{array}{c}\text { Enabling the personnel of an organization has a positive and } \\
\text { significant effect of their occupational point of view }\end{array}$ & 7.63 & 0.85 & $\begin{array}{c}\text { Greater than } 1.96 \text { and } \\
\text { accepted }\end{array}$ \\
\hline $\begin{array}{c}\text { Occupational point of view has a positive and significant effect } \\
\text { of their occupational satisfaction }\end{array}$ & 3.45 & 0.59 & $\begin{array}{c}\text { Greater than } 1.96 \text { and } \\
\text { accepted }\end{array}$ \\
\hline $\begin{array}{c}\text { Occupational point of view has a positive and significant effect } \\
\text { of their organizational commitment }\end{array}$ & 3.28 & 0.28 & $\begin{array}{c}\text { Greater than } 1.96 \text { and } \\
\text { accepted }\end{array}$ \\
\hline
\end{tabular}

This model is in a suitable condition in terms of the analogy indexes. Because the ratio between the Chi-Square and the degree of freedom is smaller than the permitted value (3) and the RMSEA value (0.072) is smaller than the permitted value $(0.08)$

\section{The model in the Standard Estimation Condition}

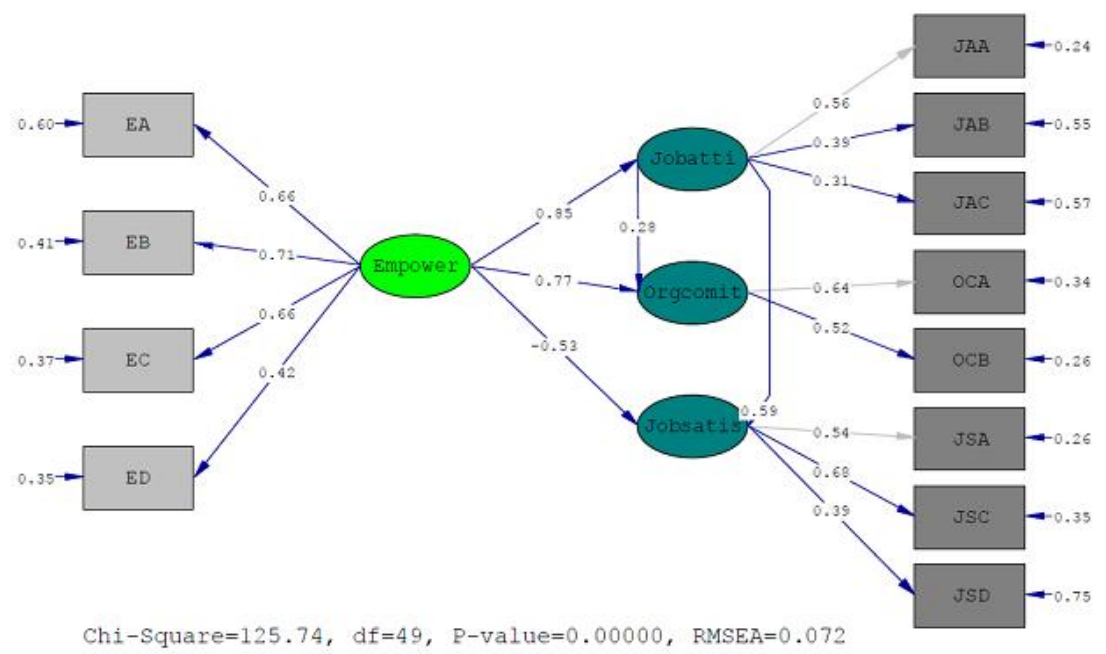




\section{The model in the Significance Value Condition}

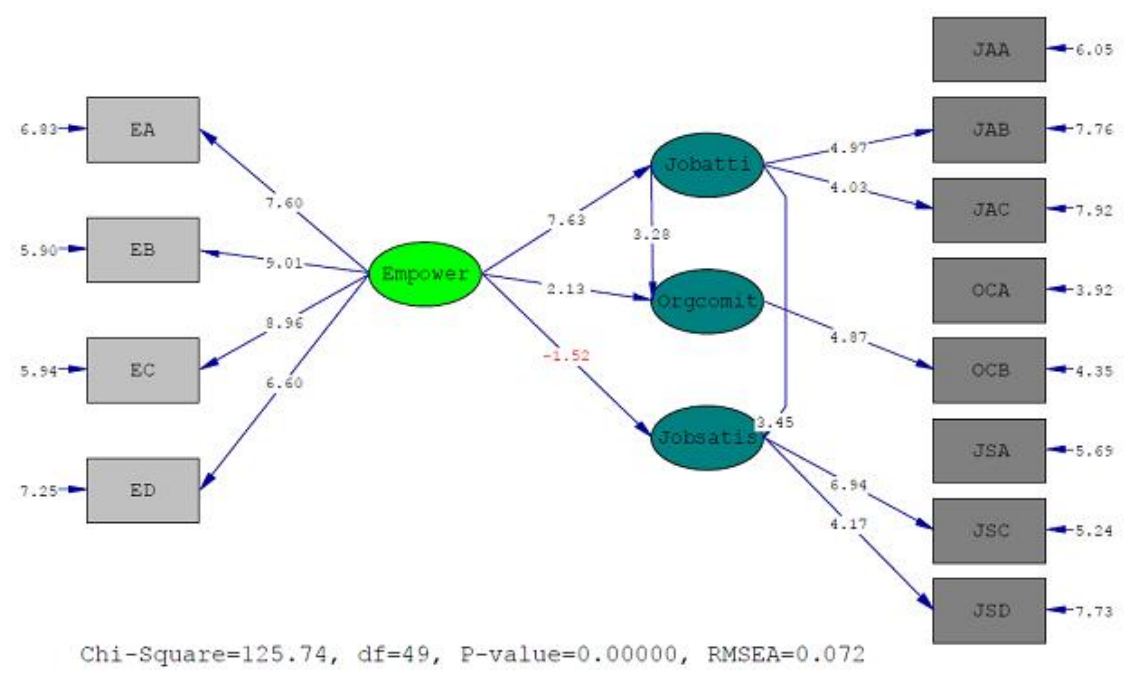

\section{Conclusions}

The first finding of the present study reveals that there are significant correlations between each of the two following variables in Samsung Corporation: Enabling the Personnel, Occupational Satisfaction, Organizational Commitment and Occupational point of view (Enabling the personnel and the occupational satisfaction, enabling the personnel and the organizational commitment, enabling the personnel and the occupational point of view, occupational point of view and the occupational satisfaction, occupational point of view and organizational commitment) In examining the findings of the research, the results of the investigation of the research hypotheses which are the correlations between enabling the personnel, occupational satisfaction, organizational commitment and occupational point of view, which in turn are the results of the structural assumptions investigations, are as follow: In the first hypothesis, enabling the personnel will increase and improve the feelings of self-efficiency, having the decision making right, being effective, being valuable, safety and self-confidence between the employees, and this leads to an increase in their occupational satisfaction. An organization is under the internal and external pressures. In the second hypothesis, enabling the personnel is the intrinsic motivation of a fourfold wisdom set namely potency, motivation, meaningfulness, autonomy; along with reflection of the personal direction in relation to the personal role in the work. In the third hypothesis, responding the competent personnel to the customer can have effects on the human resources aspect of the occupational point of view. The instruction which is done in order to enable the personnel will have effects on the organizational factors of the occupational point of view including instruction, value finding, and improvement. Therefore according to the most of the findings obtained from the previous researches, enabling the personnel leads to create a positive between the personnel about some aspects of the job in the organizations, and in the present research this is proved. About the forth hypothesis, it can be said that by considering some of the factors such as the ambient human resources, the nature of the job and the organization, organizational, environmental and personal factors which are four aspects of the job satisfaction, enabling the personnel increases the occupational satisfaction in the organization, and by increasing the occupational satisfaction the employees can observe the positive and effective effects in the human and organizational levels. This hypothesis of the research is consistent with the findings obtained from the previous studies. About the fifth hypothesis, the organizational commitment is a view about the faithfulness of employees toward the organization which through involvement of the personnel in the organizational decisions shows the attention of the personnel to the organization and success and goodness of the organization. Therefore it can be concluded that according to the mentioned definitions about the occupational point of view, positive view of the personnel of the organization about their jobs increases their interests in remaining in the organization and their commitment to the organization.

\section{Reference}

[1]. Anderson,J.C.anddGerbing,D.W.,"Structural equation modeling in practice-a review And recommended two-step approach ”,Psychological Bulletin,(1988),Vol.103, pp.411-23.

[2]. Armstrong,J.S.andOverton,T.S. "Estimating non response bias in mail surveys", Journal of Marketing Research, (1977),Vol.14,pp.396-402.

[3]. Aryee,S.andChen,Z.X."Leader-member exchange in a Chinese context: antecedents,The mediating role of psychological empowerment and outcomes ",Journal of Business Research,(2006),Vol.59,pp.793-801. 
[4]. Aycan,Z.,Kanungo,R.N.,Mendonca,M.,Yu,K.C.,Deller,J.,Stahl,G.andKurshid,A. "Impact of culture on human resource management practices: a 10-country comparison", Applied Psychology: An International Review ( Psychologie Appliquee-Revue International),(2000),Vol.49,pp.192-221.

[5]. Barak,M.E.M.,Nissly,J.A.andLevin,A.“Antecedents to retention and turnover among Child welfare, social work, and other human service employees: what can we learn from Past research ? Are view and metanalysis ",Social Service Review,.(2001),Vol.75,pp.625-61.

[6]. Gronroos, C, "Relationship approach to marketing in service contexts - the marketing and organizational-behavior interface", Journal of Business Research,(1990). Vol. 20,pp. 3-4

[7]. Allen, Myria. WatKins.1991. the relationship between communications affect ,job alternative and voluntary turnover intentions. journal citation : southern - communication -journal, vol 41, n3

[8]. Armstrong, Micheal. 1994. Handbook Personnel Management Practice. Fourth edition.Kurgan page.

[9]. blanchard, k. H \& Carlos, J. P and randloph, A. 2003. Empowerment Take More Than One Minute, Barret-Koehler. sanfrancisco.

[10]. Bowen, D. E \&Laweler, E. E. 1995. The Empowering Service workers.Sloan Management Review Summer. 